\title{
TACTICAL DECISION-MAKING SUPPORT INFORMATION FOR AIRCRAFT LIGHTNING AVOIDANCE Feasibility Study in Area of Winter Lightning
}

\author{
EIICHI YoshiKaWA AND Tomoo Ushio
}

For realizing aircraft lightning avoidance, weather and flight data were collected from actual aircraft lightning strike cases in a winter lightning area, and it was confirmed that $60 \%-80 \%$ of current aircraft lightning strikes could be avoided.

A ircraft lightning strike (see Fig. 1) is an aviation weather phenomenon that can disturb flight schedules and incur costs to airlines. There are two mechanisms of aircraft lightning strikes: aircraftintercepted lightning and aircraft-triggered lightning. The former occurs when an aircraft is coincidentally on the channel of a natural lightning discharge, while the latter is lightning that is triggered when an aircraft approaches an electrically charged cloud. As can be

AfFILIATIONS: YoSHIKAWA-Japan Aerospace Exploration Agency, Mitaka, Tokyo, Japan; UsHIO-Tokyo Metropolitan University, Hino, Tokyo, Japan

CORRESPONDING AUTHOR: Eiichi Yoshikawa,

yoshikawa.eiichi@jaxa.jp

The abstract for this article can be found in this issue, following the table of contents.

DOI:I0.II75/BAMS-D-I8-0078.I

In final form 26 November 2018

(C)2019 American Meteorological Society

For information regarding reuse of this content and general copyright

information, consult the AMS Copyright Policy. easily imagined, most aircraft lightning strikes occur because of the latter mechanism (Rakov and Uman 2003, chapter 10).

According to the AE-2 Lightning Committee (2013), commercial aircraft receive a lightning strike once every 1,000-20,000 flight hours. Since

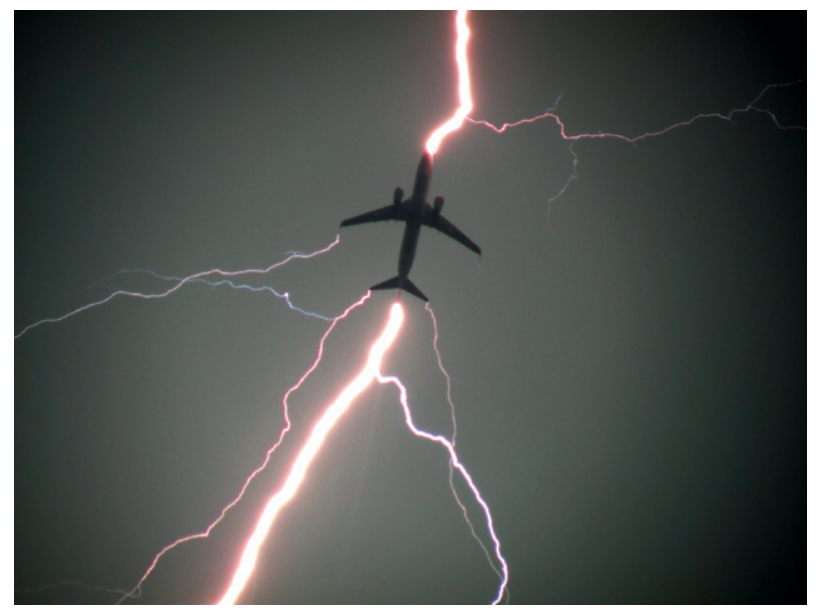

Fig. I. An aircraft lightning strike. Photograph provided by the Lightning Photo Contest, Otowa Electric Co., Ltd. 
the designed life of an aircraft is typically 60,000 100,000 flight hours, this means that an average aircraft can be expected to receive tens to hundreds of lightning strikes during its life. Since aircraft are designed, manufactured, and certified to be tolerant to lightning, aircraft lightning strikes almost never result in serious accidents. However, lightning can damage an aircraft's body and instruments, and more severe damage can force it to be withdrawn from service for repair and its following flights to be canceled. Even if the damage is minor, it may be necessary for mechanics to fully check the aircraft and sometimes make temporary repairs, which can lead to delays if they cannot be completed during the turnaround for the next service. Every year in Japan alone, the cost of repairs due to aircraft lightning strikes is estimated to be millions of dollars, and tens of flight cancellations and hundreds of delays are reported. Since recent aircraft contain more carbon composite parts that are more expensive and take longer to repair than conventional aluminum structures, the economic burden of aircraft lightning strikes will certainly become a more serious issue in the future.

When discussing lightning in Japan, the phenomenon of "winter lightning" must also be noted. Winter lightning, as its name indicates, is a particular kind of lightning that occurs only in winter. Winter lightning has frequently been reported near the Sea of Japan coast, and is known for its unique characteristics: the small amount of associated lightning (in many cases, no associated lightning) and a discharge energy several times greater than summer lightning. These characteristics make it a nightmare for pilots; it is hard to predict and it is possible to take heavy damage (Rakov and Uman 2003, chapter 8; Montanya et al. 2016; Wilkinson et al. 2013).

In 2016, a consortium of manufacturers, airlines, universities, and research institutes called "Weather Endurance Aircraft Technology to Hold, Evade and Recover by Eye" (WEATHER-Eye) was established to conduct researches to solve aviation weather issues. In 2017, the consortium published its WEATHEREye vision (WEATHER-Eye Consortium 2017), in which the member organizations jointly summarized aviation weather issues and laid out roadmaps to their solutions. Aircraft lightning strike was identified as an urgent issue, and a feasibility study on the development of tactical decision-support information for aircraft lightning avoidance was scheduled. This article presents the feasibility study, which was conducted by Japan Aerospace Exploration Agency (JAXA) and Tokyo Metropolitan University (TMU) with the cooperation of All Nippon Airways Co., Ltd. (ANA), and Japan Airlines Co., Ltd. (JAL).

AIRCRAFT LIGHTNING AVOIDANCE. Aircraft lightning strike. Many lightning strikes on the aircraft are caused not by an aircraft intercepting an already occurring lightning channel but by an aircraft triggering a lightning discharge (Mazur et al. 1984; Reazer et al. 1987; Rakov and Uman 2003). Lightning strikes on aircraft occur around an altitude of $5 \mathrm{~km}$ in the summer and within a few kilometers of them in the winter. Winter lightning is a phenomenon that is caused from a winter storm and is encountered in a coastal area of Sea of Japan and west Norway. In both cases, there is a tendency for aircraft lightning strikes to occur at altitudes where charge separation is active: that is, at temperature altitudes especially from $-5^{\circ}$ to $0^{\circ} \mathrm{C}$ (Murooka 1992). Aircraft-triggered lightning begins with positive and negative leaders propagating in opposite directions at the same time (strictly speaking, a positive leader narrowly precedes a negative leader), which is known as a bidirectional leader (Mazur 1989). After the initiation of the lightning strike, a dart leader and return stroke, which are frequently seen in natural lighting, and recoil streamers, which are current pulses propagating back to the aircraft from the tip of the positive leader, have been identified (Mazur and Moreau 1992).

Present situation. In Japan, the Japan Meteorological Agency (JMA)-operated Lightning Detection Network system (LIDEN) is used by aviation. LIDEN can locate lightning all over Japan, and users can identify lightning clouds by monitoring indications superimposed on a weather radar display. Moreover, JMA also informs lightning potential, which is estimated from measurements from LIDEN, C-band weather radar, and the predictions of a meteorological model (Kasahara 2011).

Aviation weather support information and systems are mainly classified as either strategic or tactical. Strategic support provides weather information for the en route (cruise) phase of flight; that is, it covers a wide area with forecast times greater than one hour. On the other hand, tactical support applies to the takeoff and landing phases and indicates current or nowcast (forecasts less than one hour ahead) weather information in the vicinity of airports with finer spatial resolution than strategic support. Although LIDEN has wide coverage, it is only sensitive to cloud-to-ground lightning, which constitutes about $10 \%$ of natural lightning. (Note that natural lightning can be classified as cloud to ground and intracloud. 
Intracloud lightning occur more frequently.) It is frequently reported that aircraft-triggered lightning occurs when natural lightning is inactive (almost no lightning is confirmed visually or by LIDEN). Because of its coverage and detection characteristics, LIDEN-based information is useful for aircraft in the cruise. However, many aircraft lightning strikes occur during the takeoff or landing phases. This is probably because during the cruise phase, LIDENbased information provides awareness of areas where natural lightning is occurring and aircraft are able to deviate far enough from their routes to avoid them. When a thunder cloud approaches the busy airspace around an airport, however, there is less room for maneuver and aircraft have to approach closer to it, and unfortunately take lightning strikes. Mr. Ichikawa, a JAL Boeing 777 captain, gave the following comment:

Even when the possibility of a lightning strike can be seen visually, a pilot cannot decide to avoid it, especially in busy airspace. This is because avoidance maneuvers based just on pilot feelings definitely cause traffic disturbances. In order to reduce aircraft lightning strikes, it is necessary to make avoidance decisions based on lightning potential information that is reliable and shared by pilots, controllers, and ground operations staff.

Thus, a tactical decision support system for avoiding aircraft lightning strikes is highly desirable. However, no such technology has yet been developed.

Tactical support concept. The concept of our aircraft lightning avoidance system is shown in Fig. 2. Airport-based sensors measure meteorological parameters relevant to lightning. The sensor measurements are processed to identify areas where there is a potential of aircraft lightning strikes. Based on this information, takeoff and landing aircraft can adjust their flight paths to avoid the areas or can delay or expedite takeoff or landing. For landing aircraft, the information is also useful for selecting a safe area for

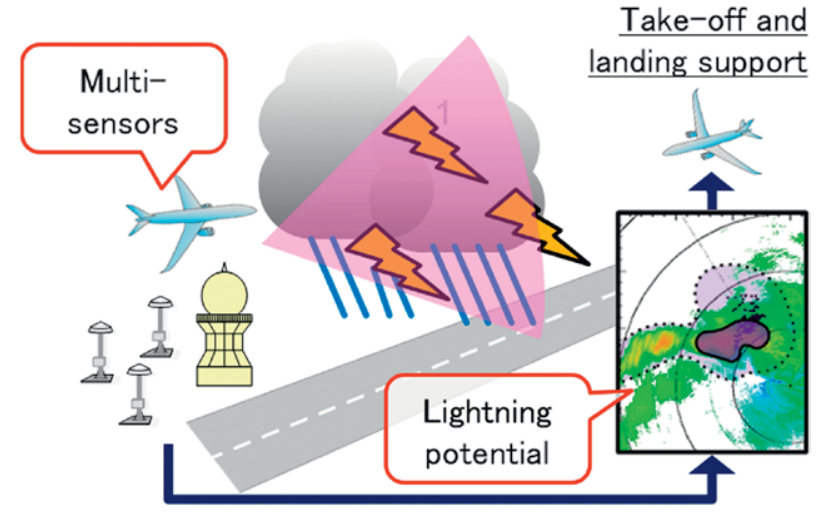

Fig. 2. Concept of a tactical support system for aircraft lightning avoidance.

holding to wait for the hazard area to move away or dissipate. Although the information can be transmitted directly to aircraft crews or relayed to them by air traffic controllers or ground-based operations support staff, it is desirable that these parties all share the same information so that avoiding action may be taken without causing undue traffic disturbances as a result of lack of common awareness.

FEASIBILITY STUDY. Data collection. A feasibility study of the tactical support concept was carried out by analyzing the datasets summarized in Table 1. Cases of actual flights around Shonai airport in Yamagata prefecture, Japan, were investigated in two winter periods, November 2015-February 2016 and November 2016-February 2017. Winter cases were examined because it is more difficult to identify aircraft lightning potential areas in that season since many meteorological structures associated with precipitation are not as apparent as in summer. The analyzed area was defined as a box bounded by $37.0^{\circ}-39.5^{\circ} \mathrm{N}$ in latitude and $138.0^{\circ}-140.5^{\circ} \mathrm{E}$ in longitude. Flight data were obtained from aircraft onboard quick access recorder (QAR) data, which include time histories of aircraft position (latitude and longitude) and air data (total air temperature, etc.) along the flight path. The data are recorded at a

TABLE I. Analysis dataset.

\begin{tabular}{|lcc|}
\hline Item & Specification & Remarks \\
\hline Time period & Nov 2015-Feb 2016, Nov 2016-Feb 2017 & - \\
\hline Area & $37.0^{\circ}-39.5^{\circ} \mathrm{N}, 138.0^{\circ}-140.5^{\circ} \mathrm{E}$ & Around Shonai airport \\
\hline Number of evaluated flights & $14 / 76$ with/without lightning strike & - \\
\hline Time of aircraft lightning strikes & Pilot reports & Recorded in minutes \\
\hline Flight data & QAR data & - \\
\hline Weather data & C-band Doppler radars at Akita, Niigata, and Sendai & Operated by JMA \\
\hline
\end{tabular}


regular time interval of a few seconds. The recorded data and recording interval vary somewhat between aircraft types. As weather data, measurements were collected from three C-band pulsed-Doppler weather radars operated by the JMA in Akita, Niigata, and Sendai prefectures. This paper utilized a measurement of reflectivity that is so-called intensity of radar echo. The locations of these weather radars and their relationship to Shonai airport are shown in Fig. 3. The dashed circles indicate the horizontal coverages of the radars, and it is seen that in combination, they observe the area around Shonai airport. The weather data are stored on spherical grids with intervals of $500 \mathrm{~m}$ in range and $0.7^{\circ}$ in azimuth, centered on each radar. Every $10 \mathrm{~min}$., each radar makes 26 constantelevation observations at elevation angles of $0^{\circ}-25^{\circ}$. Note that the radar operational specifications vary slightly between the radars. Since distances from the radars to the analyzed area can be a few hundreds of kilometers, measurements can be low resolution and elevationally sparse (beamwidth and an elevational gap between two adjacent beams can become as large as a few kilometers). In this paper, spatial structure of reflectivities is reconstructed on a coordinate system of latitude, longitude, and altitude whose axis intervals are $0.005^{\circ}, 0.005^{\circ}$, and $100 \mathrm{~m}$, respectively $\left(0.005^{\circ}\right.$ is roughly equivalent to $600 \mathrm{~m}$ ). The reconstruction is performed by averaging reflectivities in a width of $0.05^{\circ}$ in latitude and longitude and of $500 \mathrm{~m}$ in

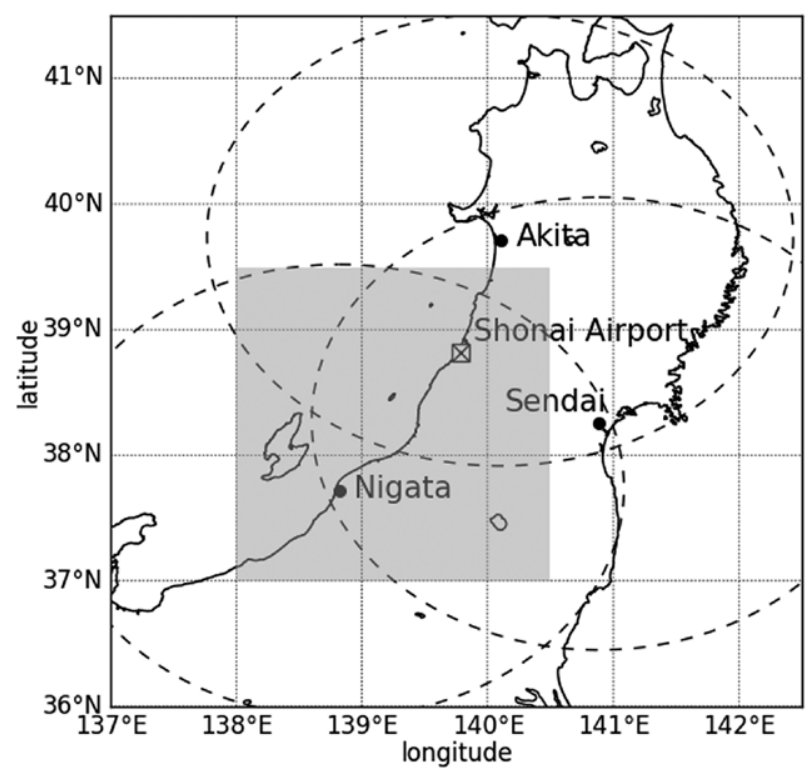

Fig. 3. Airport, radars, and feasibility study analysis area; the boxed cross indicates Shonai airport. The dots are the $C$-band weather radar sites and their coverage areas are shown by dashed lines. The analyzed area is indicated by the gray box. altitude. Fourteen cases of aircraft lightning strikes were confirmed in the analyzed area and time period, where the aircraft are medium-sized airliners and the flights continued safely in all cases. The times when the aircraft lightning strikes occurred were obtained from pilots' reports, in which time is recorded in minutes. A total of 76 cases of flights that did not sustain a lightning strike despite passing close to weather were also analyzed. These cases were selected as flights that passed near to a C-band radar echo with a strength of more than $20 \mathrm{dBZ}$ within an area more than $50 \mathrm{~km}^{2}$ at an altitude of about $1 \mathrm{~km}$.

Lightning-related parameters. Two parameters related to lightning, vertical integrated reflectivity (VIR) and $-10^{\circ} \mathrm{C}$-altitude reflectivity $\left(-10^{\circ} \mathrm{CR}\right)$, were retrieved from the weather data. Examples of horizontal profiles of VIR and $-10^{\circ} \mathrm{CR}$ are shown, respectively, in Figs. $4 \mathrm{a}$ and $4 \mathrm{~b}$. Additionally, Fig. $4 \mathrm{c}$ shows a horizontal profile of reflectivity at an altitude of $2 \mathrm{~km}$, which is widely utilized in airport operations.

A VIR is a vertical summation of C-band radar reflectivities at a certain latitude-longitude position. A horizontal profile of VIRs can indicate where precipitation is well developed vertically; $-10^{\circ} \mathrm{CR}$ is similar to VIR but the summation is performed at altitudes where the air temperature is around $-10^{\circ} \mathrm{C}$, where cloud electrification occurs (Takahashi 1978). [According to Takahashi (1978), it was confirmed in laboratory experiments that the magnitude of riming electrification highly depended on air temperature and cloud water content. Since it is practically difficult to obtain data of cloud water content, this study uses only air temperature.] In this study, vertical profiles of air temperature were retrieved from flight data assuming that air temperatures are horizontally constant in the analyzed area, and $-10^{\circ} \mathrm{CR}$ was calculated by summing reflectivities at temperatures from $-9^{\circ}$ to $-11^{\circ} \mathrm{C}$. It must be noted here that $-10^{\circ} \mathrm{CR}$ is retrieved from reflectivities that are reconstructed from low-resolution and sparse measurements as stated in the previous subsection. (Accuracy of $-10^{\circ} \mathrm{CR}$ would be improved by applying a locally installed or an airborne weather radar.) In the example of Fig. 4, which resulted from observations at 0736:25 Japan standard time (JST) 16 December 2016, altitudes of $-9^{\circ}$ to $-11^{\circ} \mathrm{C}$ are calculated to 1.28 and $1.55 \mathrm{~km}$, respectively. Comparing VIRs with reflectivity at $2-\mathrm{km}$ altitude showed a lot of disparity between the two. While it seems that the echo patterns agreed north of $39.0^{\circ} \mathrm{N}$, strong echoes of VIR were spread more widely than reflectivity at $2-\mathrm{km}$ altitude in a part of $38.0^{\circ}-38.5^{\circ} \mathrm{N}$ and a western part of $37.0^{\circ}-38.0^{\circ} \mathrm{N}$. Comparisons of 
$-10^{\circ} \mathrm{CR}$ and reflectivity at $2-\mathrm{km}$ altitude showed more consistency in this case. This is because altitudes of $-10^{\circ} \mathrm{C}$ are estimated to be $1.28-1.55 \mathrm{~km}$, and weather radars' angular resolution at such low altitudes is very low. When an altitude of $-10^{\circ} \mathrm{C}$ is more different from $2 \mathrm{~km},-10^{\circ} \mathrm{CR}$ is more useful compared to reflectivity at $2-\mathrm{km}$ altitude, and it is more precisely retrieved by using a weather radar that is installed close to the airport.

Spatial relationships between aircraft and lightningrelated parameters. Figures $5 \mathrm{a}-\mathrm{c}$ show horizontal profiles of VIR observed at 10-min intervals from 0725 to 0745 JST 16 December 2016 for a case in which an aircraft lightning strike occurred. The triangle in each plot shows the aircraft's position, and the red triangle in Fig. 5c indicates where the aircraft was struck by lightning. The aircraft appeared at about $37.8^{\circ} \mathrm{N}$, $140.1^{\circ} \mathrm{E}$ in Fig. $5 \mathrm{a}$ and flew north before circling in Fig. 5b, probably to wait for bad weather to move away before starting its approach. Finally, as shown in Fig. 5c, the aircraft took a lightning strike just before landing. The khaki-colored lines in the figures indicate the spatial relationships between VIRs and the aircraft. For example, in each subfigure, a solid line connects the aircraft and a plus symbol annotated with " $>15 \mathrm{~dB}$," which indicates the location of the VIR stronger than $15 \mathrm{~dB}$, which is closest to the aircraft. Similarly, Figs. $6 \mathrm{a}-\mathrm{c}$ show, respectively, the horizontal profiles of $-10^{\circ} \mathrm{CR}$ at 0725,0735 , and $0745 \mathrm{JST}$. In this case, both Figs. 5 and 6 indicate that a lightning strike occurred when the aircraft approached an area with heavy echoes of VIR and $-10^{\circ} \mathrm{CR}$. Time histories of the echo proximities, indicated by khaki lines, are shown in Fig. 7. In Fig. 7a, minimum distances to the aircraft from areas of VIRs $>15,>25$, and $>35 \mathrm{~dB}$ are shown by solid, dashed, and dotted lines, respectively. In Fig. $7 \mathrm{~b}$, minimum distances from areas of $-10^{\circ} \mathrm{CR}$ $>10,>15$, and $>20 \mathrm{~dB}$ are shown by solid, dashed, and dotted lines, respectively. It is seen that the minimum distances from areas of VIR $>15$ and $>25 \mathrm{~dB}$ and areas of $-10^{\circ} \mathrm{CR}>10,>15$, and $>20 \mathrm{~dB}$ decreased rapidly just before the lightning strike occurred. Although the minimum distances from areas of VIR $>35 \mathrm{~dB}$ did not significantly change around the time of the lightning strike, this is merely because the cloud associated with the aircraft lightning strike was not developed as far as VIR $>35 \mathrm{~dB}$ or $-10^{\circ} \mathrm{CR}>20 \mathrm{~dB}$.

Aircraft lightning potential areas. Aircraft lightning potential areas can be classified by thresholding the spatial relationships between aircraft and weather radar echoes. Although heavy echoes are more likely to cause aircraft lightning strikes, they miss the detection of aircraft lightning potential areas since they do not appear frequently. On the other hand, light
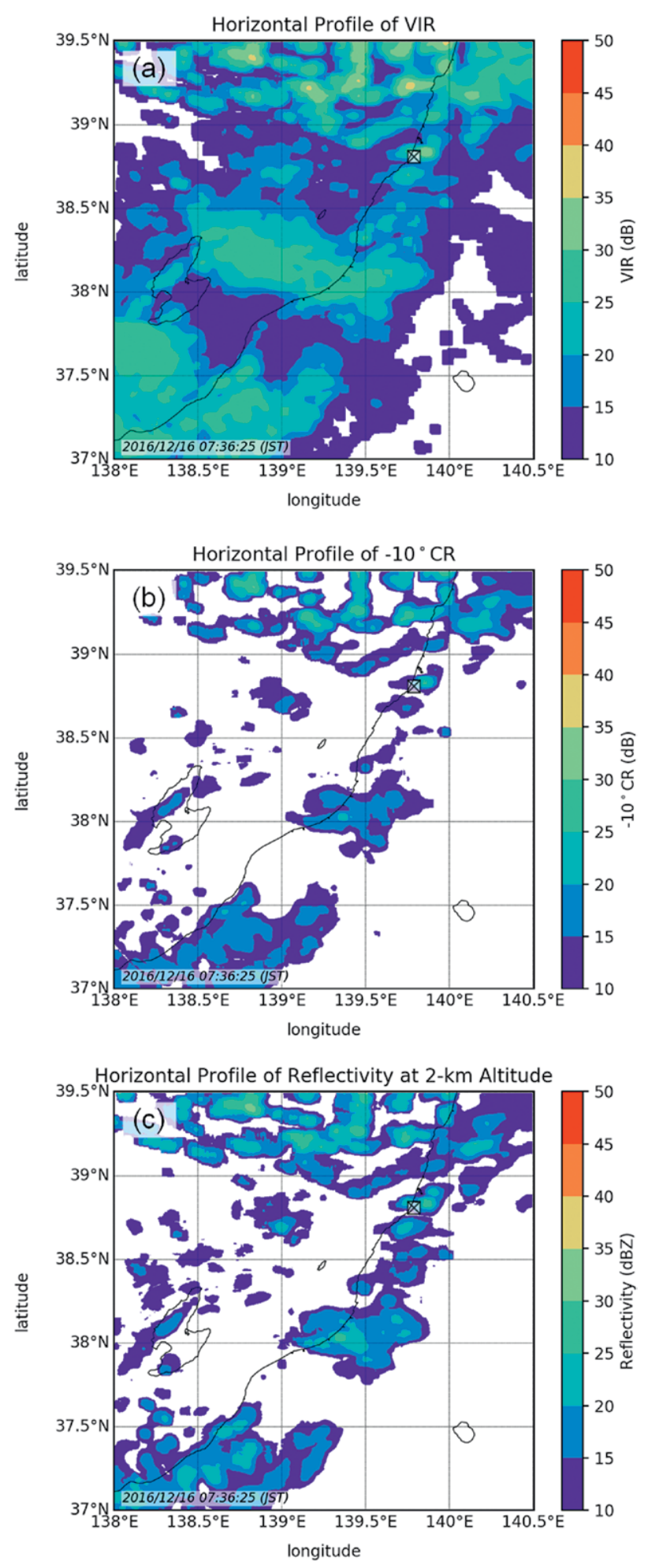

Fig. 4. An example of lightning-relative parameters: (a) VIR and (b) $-10^{\circ} \mathrm{CR}$. (c) Reflectivity at 2-km altitude, which is widely used in airport meteorological observations. The boxed cross indicates Shonai airport. 
echoes lead to false alarms since they are widespread in bad weather. In this study, therefore, the closest proximities of VIR $>25 \mathrm{~dB}$ and of $-10^{\circ} \mathrm{CR}>15 \mathrm{~dB}$ to
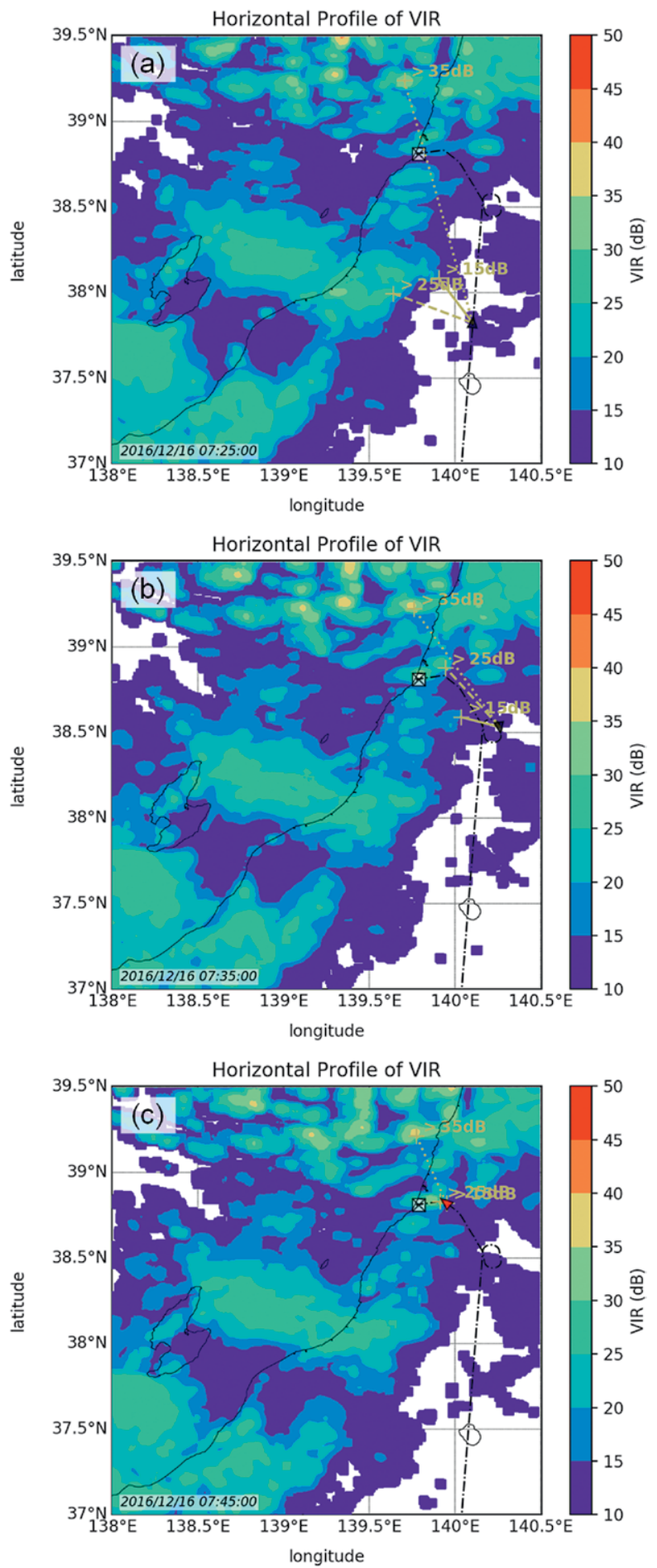

FIG. 5. Spatial relationships between aircraft and VIRs at (a) 0725, (b) 0735, and (c) $0745 \mathrm{JST}$. Aircraft positions are indicated by triangles. The positions of the VIRs more than 15, 25, and $35 \mathrm{~dB}$ closest to the aircraft are connected to it by Khaki solid, dashed, and dotted lines, respectively. The boxed cross indicates Shonai airport. an aircraft were adopted for lightning potential area detection, and were calculated every minute for all the flight cases analyzed. A scatterplot of these distances
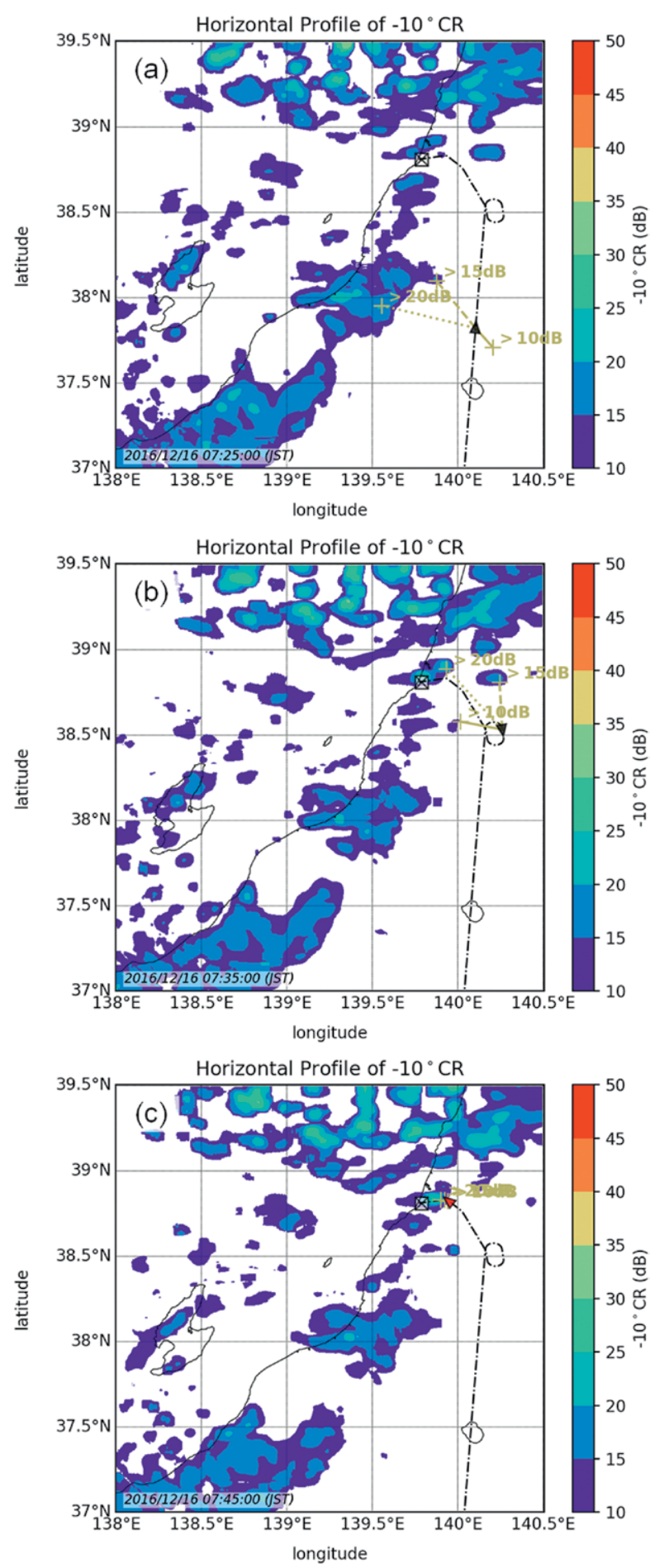

Fig. 6. Spatial relationships between aircraft and $-10^{\circ} \mathrm{CRs}$ at (a) 0725, (b) 0735, and (c) $0745 \mathrm{JST}$. Aircraft positions are indicated by triangles. The positions of the $-10^{\circ} \mathrm{CR}$ more than 10, 15, and $20 \mathrm{~dB}$ closest to the aircraft are connected to it by khaki solid, dashed, and dotted lines, respectively. The boxed cross indicates Shonai airport. 
expressed in minutes is shown in Fig. 8. The distances at the times of lightning strikes are shown by blue dots. When there was no $-10^{\circ} \mathrm{CR}$ echo stronger than $15 \mathrm{~dB}$ in the analyzed area, the minimum distance of $-10^{\circ} \mathrm{CR}>15 \mathrm{~dB}$ was set at $100 \mathrm{~km}$. This study defined two thresholds. One is a single condition where the proximity to a VIR $>25 \mathrm{~dB}$ is less than $15 \mathrm{~km}$, shown by yellow or red in Fig. 8 . The other is a dual condition where the proximity to a VIR $>25 \mathrm{~dB}$ is less than $15 \mathrm{~km}$ and the proximity to a $-10^{\circ} \mathrm{CR}>15 \mathrm{~dB}$ is less than $5 \mathrm{~km}$, shown by red. These single and dual conditions are to identify areas of high and moderate lightning potential, respectively.

Table 2 shows probability of detection (POD) and false alarm rate (FAR) for the high and moderate potential conditions. The POD is the ratio at which the selected thresholds indicate a potential of lightning strikes and aircraft lightning strikes actually occur,
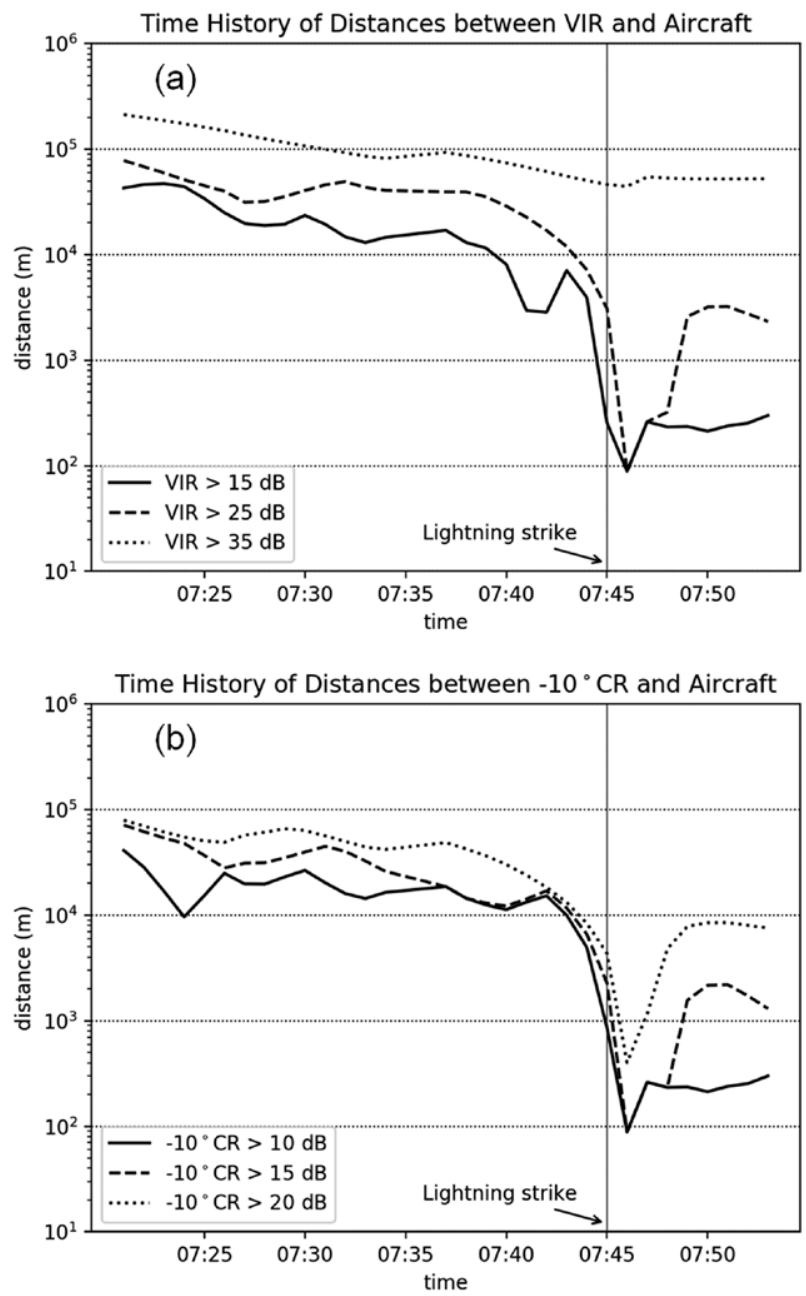

FIG. 7. Time histories of distances between aircraft and lightning-related parameters: (a) VIR and (b) $-10^{\circ} \mathrm{CR}$. Vertical thin solid lines indicate the time at which the aircraft lightning strike occurred. while the FAR is the ratio at which the thresholds indicate lightning potential but aircraft lightning strikes do not occur. The ratios are calculated by testing the thresholds every one minute. The moderate potential condition is superior in POD and inferior in FAR to the high potential condition; that is, it achieves a greater POD and lower FAR. The moderate potential area can give an indication of lightning strike possibility over a wide area and can be considered as reasonably reliable flight safety advisory information. On the other hand, the high potential area gives warnings over a narrower area but with fewer false alarms, and is more suitable as alerting information.

Figure 9 demonstrates both potential areas overlaid on horizontal profiles of reflectivities at an altitude of $2 \mathrm{~km}$. The case is the same as that shown in Figs. 5 and 6. The moderate potential areas, shown by yellow, cover a wide area as advisory information.

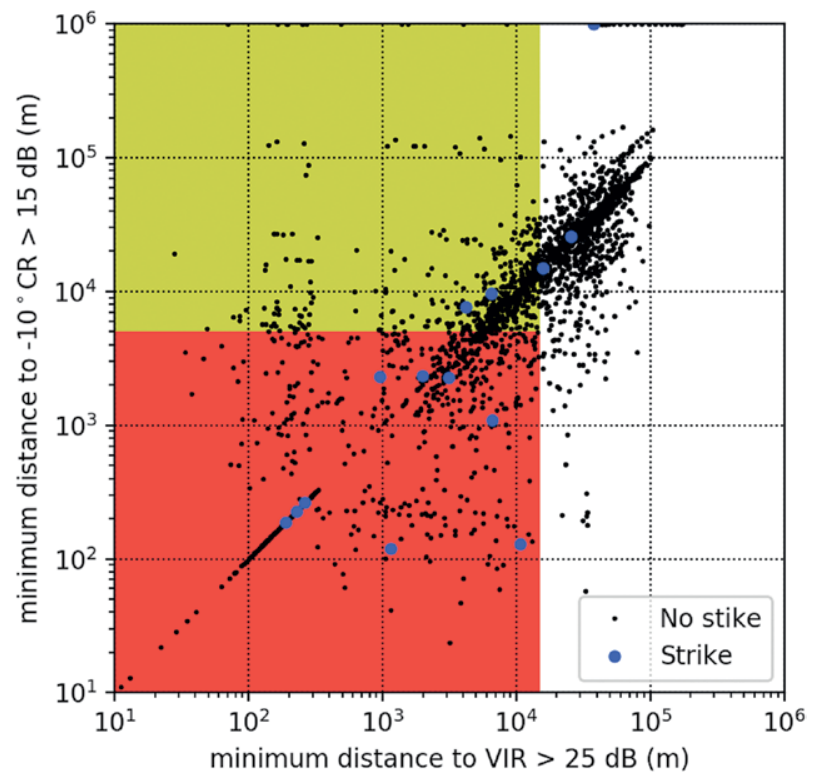

Fig. 8. Scatterplot of distances between aircraft positions and the closest VIR of $25 \mathrm{~dB}$ threshold and closest $-10^{\circ} \mathrm{CR}$ of I5-dB threshold; Blue and black dots indicate points with and without aircraft lightning strikes, respectively. Points at which $-10^{\circ} \mathrm{CR}$ of $15 \mathrm{~dB}$ threshold were not observed are plotted at $100 \mathrm{~km}$ on the $y$ axis.

\begin{tabular}{|llc|}
\hline \multicolumn{3}{|l|}{ TABLE 2. Statistical scores. } \\
\hline Potential level & \multicolumn{1}{l|}{ POD } & FAR \\
\hline High & $64 \%(9 / 14)^{*}$ & $29 \%(670 / 2,337)^{* *}$ \\
\hline Moderate & $79 \%(I I / 14)^{*}$ & $55 \%(\mathrm{I}, 278 / 2,337)^{* *}$ \\
\hline${ }^{*}[\mathrm{TP} /(\mathrm{TP}+\mathrm{FN})] ;$ & True positive (TP), false negative (FN) \\
${ }^{* *}[\mathrm{FP} /(\mathrm{FP}+\mathrm{TN})] ;$ & False positive (FP), true negative (TN)
\end{tabular}


Meanwhile, the high potential areas, shown by red circles, cover limited areas as alerting information. As shown in Figs. 9a and 9b, the aircraft had flown
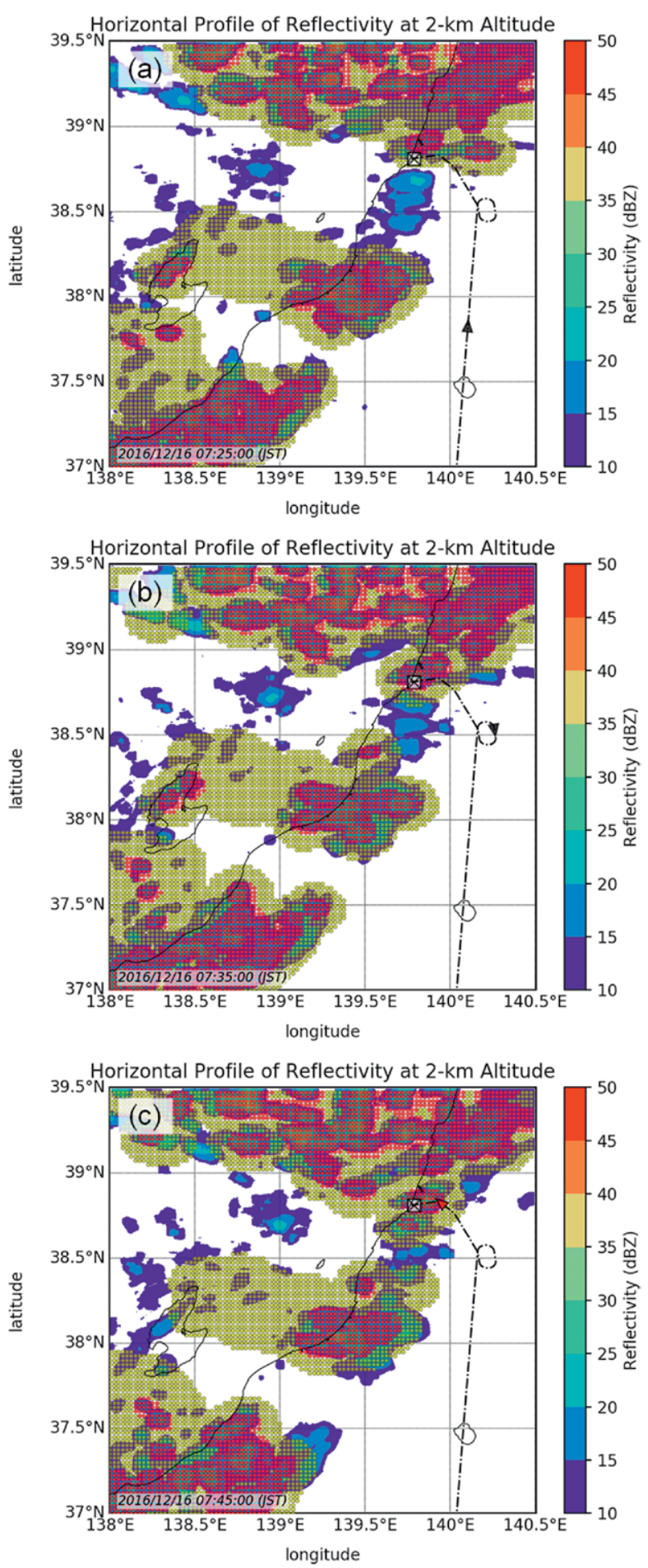

Fig. 9. Aircraft lightning potential areas at (a) 0725, (b) 0735, and (c) $0745 \mathrm{JST}$. Aircraft position is indicated by triangles. Areas of high and moderate lightning potential areas are represented by red and yellow circles, respectively. The boxed cross indicates Shonai airport. about $10 \mathrm{~km}$ or more from the yellow area, and received a lightning strike in the high potential area covering Shonai airport as shown in Fig. 9c. Also in Fig. 9, discrepancies are seen between the reflectivity at 2-km altitude and the potential areas; in particular, the high potential area cannot be deduced from the reflectivity at $2-\mathrm{km}$ altitude. It is therefore expected that information regarding aircraft lightning potential areas will help aircraft avoid lightning strikes and realize more efficient airport operations.

FUTURE PLANS. Road to actual operation. The results of this study indicate that detection of aircraft lightning potential areas is feasible. The scores of POD and FAR derived from the analyses are considered sufficient to justify the implementation of such a system because avoidance of $64 \%$ or $79 \%$ of aircraft lightning strikes should result in an economic benefit to commercial aircraft operations. Meanwhile, it is important to suppress FAR since a high FAR such as 55\% could decrease the economic benefit by lowering operational efficiency. For realizing actual operation, however, two main tasks remain. One is to make further evaluation of the system's performance with more cases. Since this paper demonstrated the feasibility with just fourteen cases of aircraft lightning strikes, a more reliable evaluation with further cases including ones around other airports is required. Moreover, the feasibility study only looked at winter cases. Since precipitation structures in winter are less apparent than summer, it can be said that feasibility was demonstrated in difficult cases (in cases with apparent precipitation structure in summer, it is probably easy to identify aircraft lightning potential areas.) Evaluation including summer cases is, however, required, and it is anticipated that some adjustments to the thresholds may be needed.

The other task is to change the data sources. The feasibility study used a combination of ground-based and airborne sensors: ground-based C-band weather radars to detect echoes and aircraft-measured temperatures to extract vertical air temperature profiles. The detection of aircraft lightning potential areas might be easier to implement if it can use either only ground-based sensors or only aircraft-based sensors; $-10^{\circ} \mathrm{CR}$ can be calculated using data from both ground-based C-band weather radar and aircraft on-board weather radar, so C-band radar data can be replaced with airborne radar data, albeit with a loss of data quality. Vertical air temperature profiles could be measured by ground-based methods such as radiosondes as well as aircraft sensing. 
Promising sensors. To further improve the POD and reduce the FAR, it is desirable to increase the scanning performance of the weather radar or to adopt additional sensors.

The start of cloud formation can be detected by weather radar. To achieve early detection of clouds, it is useful to have a fast-scanning weather radar such as a phased array weather radar (Mizutani et al. 2018) or a Ku-band broadband radar (Yoshikawa et al. 2010). In particular, phased array weather radar is promising in that it has realized very fast-scanning rates of 100 elevation angle observations in $30 \mathrm{~s}$. Although phased array weather radar was originally developed for the early detection of severe weather, its fast-scanning capability would contribute not only to the detection of aircraft lightning potential areas but also to the observation of other aviation weather phenomena. Weather radar networking is also effective for increasing observation frequency (Junyent et al. 2010; Yoshikawa et al. 2012) if a desired location is observed by multiple radars. Since each of these radars supposed to observe local weather, they observe at low altitudes densely with high resolution. Their dense and high-resolution data would greatly improve $-10^{\circ} \mathrm{CR}$ retrieval in winter, which mainly depends on reflectivities in low altitudes. (In other words, it is difficult for radars installed hundreds of kilometers from an airport to make sufficient aviation weather supports.)

Air temperature vertical profile is important for detecting altitudes at which precipitation creates electrostatic charge. Radiosonde is the most accurate for measuring air temperature vertical profile, and a scheme gathering radiosondes' measurements worldwide has already been established (see http://weather .uwyo.edu/upperair/sounding.html). Air temperature vertical profile is also obtained from secondary surveillance radar (SSR) mode S information downlink (Senoguchi 2015). Its measurement is more frequent and airport local but (possibly) less accurate. Since SSR mode $S$ can provide aircraft-sensed air temperatures to ground-based receivers, the data are easily obtainable using current surveillance infrastructure. SSR mode $S$ is now being introduced widely.

When clouds start charging, the increasing electric field can be sensed by a ground-based electric field mill. Since a ground-based field mill covers only a narrow area of about $10 \mathrm{~km}$, a network of distributed electric field mills is desired (Kudo and Kamogawa 2018). After natural lightning discharges from a cloud start, it is better for aircraft not to approach that cloud. Since high spatial resolution is important for airport coverage, high-sensitivity lightning location systems such as Lightning Mapping Array (LMA;
Thomas et al. 2004) and Broadband Observation network for Lightning and Thunderstorm (BOLT; Ushio et al. 2015) are promising for airport installation, although they are designed for other applications.

ACKNOWLEDGMENTS. The authors would like to thank All Nippon Airways Co., Ltd., for providing QAR data and reports of aircraft lightning strikes. The authors also thank Mr. M. Ichikawa of Japan Airlines Co., Ltd.; Dr. S. Yoshida and Mr. S. Hayashi of the Meteorological Research Institute; Dr. K. Michimoto of Otowa Electric Co., Ltd.; Prof. M. Ishii of the University of Tokyo; and Prof. V. Chandrasekar of Colorado State University for productive discussions.

\section{REFERENCES}

AE-2 Lightning Committee, 2013: Aircraft lightning environment and related test waveforms. Society of Automotive Engineers International Tech. Rep. ARP5412B, 63 pp.

Junyent, F., V. Chandrasekar, D. McLaughlin, E. Insanic, and N. Bharadwaj, 2010: The CASA integrated project 1 networked radar system. $J$. Atmos. Oceanic Technol., 27, 61-78, https://doi .org/10.1175/2009JTECHA1296.1.

Kasahara, S., 2011: Kaminari nowcast ni okeru kaminari no kaiseki: Yosokugijutu to riyouhouhou (Lightning analysis in lightning nowcast: Forecast technology and utilization). Wea. Serv. Bull., 78 (3), 95-140.

Kudo, T., and M. Kamogawa, 2018: Lightning early warning systems based on ground-based field mill network. 16th Int. Conf. on Atmospheric Electricity, Nara, Japan, International Commission on Atmospheric Electricity-Society of Atmospheric Electricity of Japan, 1-4.

Mazur, V., 1989: A physical model of lightning initiation on aircraft in thunderstorms. J. Geophys. Res., 94, 3326-3340, https://doi.org/10.1029 /JD094iD03p03326.

— ning: Processes following strike initiation that affect aircraft. J. Aircr., 29, 575-580, https://doi .org/10.2514/3.46204.

—, B. D. Fisher, and J. C. Gerlach, 1984: Lightning strikes to an airplane in a thunderstorm. J. Aircr., 21, 607-611, https://doi.org/10.2514/3.45030.

Mizutani, F., T. Ushio, E. Yoshikawa, S. Shimamura, H. Kikuchi, M. Wada, S. Satoh, and T. Iguchi, 2018: Fast-scanning phased-array weather radar with angular imaging technique. IEEE Trans. Geosci. Remote Sens., 56, 2664-2673, https://doi.org/10.1109 /TGRS.2017.2780847. 
Montanya, J., and Coauthors, 2016: Global distribution of winter lightning: A threat to wind turbines and aircraft. Nat. Hazards Earth Syst. Sci., 16, 1465-1472, https://doi.org/10.5194/nhess-16-1465-2016.

Murooka, Y., 1992: A survey of lightning interaction with aircraft in Japan. Res. Lett. Atmos. Electr., 12, 101-106.

Rakov, V. A., and M. A. Uman, 2003: Lightning: Physics and Effects. Cambridge University Press, $687 \mathrm{pp}$

Reazer, J. S., A. B. Serrano, L. C. Walko, and H. D. Burket, 1987: Analysis of correlated electromagnetic fields and current pulses during airborne lightning attachments. Electromagnetics, 7, 509-539, https:// doi.org/10.1080/02726348708908196.

Senoguchi, A., 2015: DAPs potential and an analysis on weather uncertainty for TBO. Asia/Pacific Meteorology/Air Traffic Management Seminar, International Civil Aviation Organization, Tokyo, Japan, SP/12.

Takahashi, T., 1978: Riming electrification as a charge generation mechanism in thunderstorms. J. Atmos. Sci., 35, 1536-1548, https://doi.org/10.1175/1520 -0469(1978)035<1536:REAACG>2.0.CO;2.

Thomas, R. J., P. R. Krehbiel, W. Rison, S. J. Hunyady, W. P. Winn, T. Hamlin, and J. Harlin, 2004: Accuracy of the Lightning Mapping Array. J. Geophys. Res., 109, D14207, https://doi.org/10.1029/2004JD004549.

Ushio, T., T. Wu, and S. Yoshida, 2015: Review of recent progress in lightning and thunderstorm detection techniques in Asia. Atmos. Res., 154, 89-102, https:// doi.org/10.1016/j.atmosres.2014.10.001.

WEATHER-Eye Consortium, 2017: WEATHER-Eye vision. Japan Aerospace Exploration Agency Tech. Rep., 76 pp.

Wilkinson, J. M., H. Wells, P. R. Field, and P. Agnew, 2013: Investigation and prediction of helicoptertriggered lightning over the North Sea. Meteor. Appl., 20, 94-106, https://doi.org/10.1002/met.1314.

Yoshikawa, E., T. Ushio, Z. Kawasaki, T. Mega, S. Yoshida, T. Morimoto, K. Imai, and S. Nagayama, 2010: Development and initial observation of high-resolution volume-scanning radar for meteorological application. IEEE Trans. Geosci. Remote Sens., 48, 3225-3235, https://doi.org/10.1109 /TGRS.2010.2045762.

- _ - _ , and V. Chandrasekar, 2012: Dualdirectional radar observation for preliminary assessment of the $\mathrm{Ku}$-band broadband radar network. J. Atmos. Oceanic Technol., 29, 1757-1768, https://doi.org/10.1175/JTECH-D-12-00012.1.

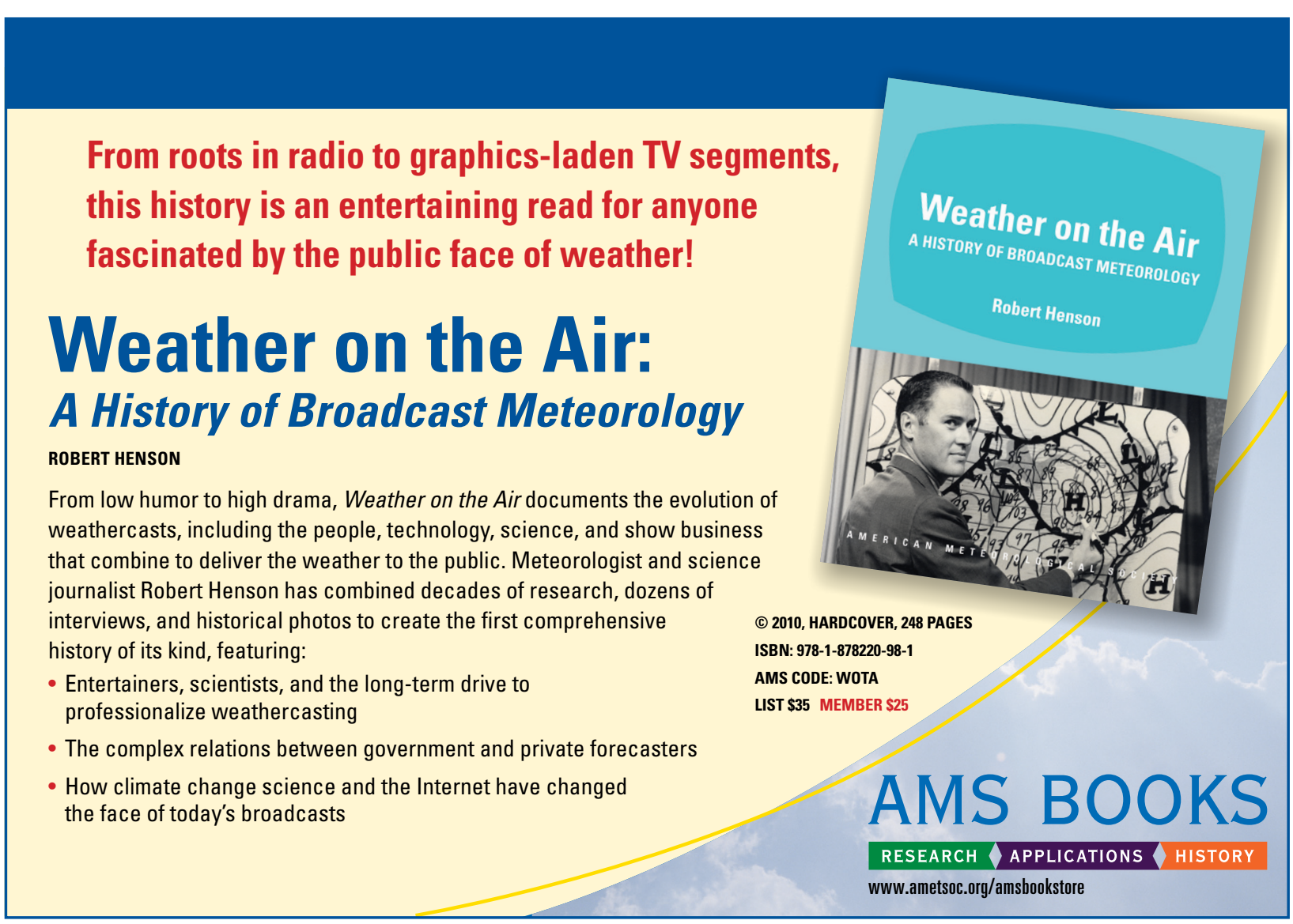

